\title{
Satisfação no trabalho e qualidade de vida de professores universitários brasileiros: revisão integrativa
}

Job satisfaction and quality of life of brazilian university professors: integrative review

\section{Satisfacción y calidad de vida en el trabajo de profesores universitarios brasileños: revisión integrativa}

\author{
Elen Villegas Campos ${ }^{1}$ \\ Alexandra Maria Almeida Carvalho ${ }^{2}$ \\ Albert Schiaveto de Souza ${ }^{3}$
}

${ }^{1}$ Mestranda em Saúde e Desenvolvimento na Região Centro-Oeste, pela Universidade Federal de Mato Grosso do Sul (UFMS). Especialista em Enfermagem do Trabalho e em Gestão no Trabalho e Educação em Saúde.

Formada em Enfermagem na UFMS. E-mail: elenvillegas@hotmail.com,

Orcid: http://orcid.org/0000-0002-6751-0131

${ }^{2}$ Doutora em Biosystems Eng. and Environmental Science, The University of Tennessee. Mestre em Engenharia Elétrica pela Universidade Federal de Uberlândia (UFU). Graduada em Engenharia Civil pela Universidade Estadual Paulista Júlio de Mesquita Filho (UNESP). Professora adjunta da Universidade Federal de Mato Grosso do Sul (UFMS) e coordenadora do Programa de PósGraduação Saúde e Desenvolvimento na Região Centro-Oeste. Atualmente desenvolve projetos em saúde ambiental, saúde do trabalhador e avaliação de serviços de saúde. E-mail: profalexandraufms@gmail.com, Orcid: http://orcid.org/0000-0002-7868-3214

${ }^{3}$ Pós-doutor pela University of Oxford, UK. Doutor e mestre em Ciências (Fisiologia) pela Universidade de São Paulo (USP), campus Ribeirão Preto. Graduado em Fisioterapia pela Universidade Estadual de Londrina (UEL).

Professor associado, ao nível de graduação, orientador credenciado no Programas de Pós-Graduação em Saúde e Desenvolvimento na Região Centro-

Oeste e em Odontologia da Universidade Federal de Mato Grosso do Sul (UFMS). Colaborador no Programa de Mestrado em Farmácia da UFMS e Mestrado em Biotecnologia da Universidade Católica Dom Bosco (UCDB), em convênio com a UFMS. Diretor do Instituto de Biociências da UFMS. Avaliador do INEP/MEC para o curso de Fisioterapia.E-mail: albertss@hotmail.com, Orcid: http://orcid.org/0000-0003-0017-672X 
Resumo: A satisfação no trabalho e a qualidade de vida determinam a condição de saúde dos professores universitários e interferem no processo de ensino- aprendizagem. Objetivo: Avaliar a satisfação no trabalho e a qualidade de vida de professores universitários de instituições no Brasil. Método: Revisão integrativa de artigos publicados entre janeiro de 2008 e janeiro de 2018. A coleta de dados foi realizada nas bases de dados: Directory of Open Access Journals, SciELO, LILACS, PubMed, e Academic One File. Para busca no inglês, foram utilizados descritores exatos do Medical Subjects Headings (MeSH): "quality of life", "job satisfaction", "faculty" e "Brazil" e em português, os Descritores em Ciências de Saúde (DeCS): "qualidade de vida" "docentes", "universidades", e o sinônimo "satisfação no trabalho". Resultados: Os docentes, em sua maioria, estão satisfeitos com o trabalho que realizam, assim como apresentam uma qualidade de vida satisfatória.

Palavras-chave: docentes; qualidade de vida; satisfação; trabalho; universidades.

Abstract: Job satisfaction and quality of life determine the health condition of university
professors and interfere in the teaching- learning process. Objective: evaluate the quality of
life and job satisfaction of university professors of institutions in Brazil. Method: Integrative
review of papers published between January 2008 and January 2018. The data collection
was made in the data bases: Directory of Open Access Journals, SciELO, Lilacs, PubMed,
and Academic One File. For English search, the following exact descriptors of Medical
Subjects Headings (MeSH) were used: "Quality of Life", "Job Satisfaction", "Faculty" and
"Brazil" and in Portuguese, Descriptors in Health Sciences (DeCS) were used: "qualidade de
vida" "docentes", "universidades", and the synonym "satisfação no trabalho". Results: the
professors, mostly, are satisfied with the work they do, and have a satisfactory quality of life.

Keywords: teachers; quality of life; satisfaction; work; universities.

Resumen: La satisfacción em el trabajo y lacalidad de vida determinan La condición de salud de los profesores universitarios y interfiere em el proceso de enseño- aprendizaje. Objetivo: evaluar la calidad de vida y La satisfacción em el trabajo de profesores universitarios de instituciones en Brasil. Método: Revisión integrativa de artículos publicados entre enero de 2008 y enero de 2018. La recolección de datos fue em lãs bases de datos: Directory of Open Access Journals, SciELO, Lilacs, PubMed, y Academic One File. Para La búsqueda em inglés, se utilizaron descriptores exactos de Medical Subjects headings (MeSH): "quality of life", "job satisfaction", "faculty" y "Brazil" y portugués, los descriptores- Descritores em Ciências de Saúde (DeCS): "qualidade de vida" "docentes", "universidades", y el sinónimo "satisfação no trabalho". Resultados: Los maestros, em su mayoría, están satisfechos com el trabajo que realizan, así como presentan una calidad de vida satisfactoria.

Palabras clave: maestros; calidad de vida; satisfacción; trabajo; universidades. 
Satisfação no trabalho e qualidade de vida e de professores universitários brasileiros:

revisão integrativa

\section{INTRODUÇÃO}

Segundo o Censo da Educação Superior 2017, havia no Brasil 2.448 instituições de Ensino Superior, com 214.608 docentes (ativos e afastados). A carreira de professor universitário é exercida por profissionais de diversas formações. No seu cotidiano, o professor prepara e ministra aulas, avalia seus alunos por meio de atividades práticas e teóricas. Nas universidades, pode atuar na graduação e na pós graduação, onde também realiza pesquisas científicas, projetos, que geram dissertações, teses e artigos científicos. Alguns exercem atividades de extensão universitária por meio das quais levam conhecimento e assistência à comunidade.

Todo ambiente de trabalho é palco de alegrias e tristezas. O trabalho ocupa a maior parte do tempo das pessoas. A profissão docente é caracterizada por um desgaste mental e intelectual, que vai além da ministração de aulas, uma vez que inclui o planejamento de atividades, correção de produções de alunos, atualização profissional, produção científica, entre outros. Essas atividades, muitas vezes, são realizadas fora do horário e do ambiente universitário. O docente leva trabalho para realizar em casa, em horários que deveria utilizar para descansar, como noites, finais de semana e feriados, sacrificando seu convívio familiar e social, o que prejudica a qualidade de vida desses trabalhadores.

A satisfação com o trabalho docente está relacionada principalmente à realização pessoal pela escolha da profissão. Porém o docente pode se sentir insatisfeito devido a alguns fatores, entre eles, a sobrecarga no trabalho, relações interpessoais entre seus pares e alunos, infraestrutura precária, falta de reconhecimento profissional, dificuldades financeiras para realização de pesquisas, exigências para produção científica (publicar ou padecer), entre outros.

A qualidade de vida está diretamente ligada à satisfação com o trabalho. A organização Mundial da Saúde 2015 definiu a qualidade de vida como sendo a percepção do indivíduo de sua inserção na vida, no contexto da cultura e sistemas de valores nos quais ele vive e em relação aos seus objetivos, expectativas, padrões e preocupações. Envolve o bem-estar espiritual, físico, mental, psicológico e emocional, além de relacionamentos 
sociais, como família e amigos e, também, saúde, educação, habitação, saneamento básico e outras circunstâncias da vida.

Diante disso, este estudo objetivou analisar estudos científicos que avaliaram a satisfação no trabalho e a qualidade de vida de professores universitários brasileiros através de uma revisão integrativa.

\section{MATERIAL E MÉTODOS}

A revisão integrativa é um método de revisão específica que sintetiza estudos já publicados sobre um tema específico a fim de favorecer um entendimento maior sobre determinado assunto. Esta revisão integrativa utilizou as cinco etapas propostas por Whittemore e Knafl (2005), identificadas na Figura 1.

Figura 1 - Etapas de uma revisão integrativa segundo Whittemore e Knafl (2005)



Fonte: elaborada pelos autores. 
Satisfação no trabalho e qualidade de vida e de professores universitários brasileiros:

\section{Etapa 1 - Identificação do problema}

O problema foi identificado por variáveis de interesse da questão norteadora "Como está a satisfação no trabalho e a qualidade de vida do professor universitário de instituições no Brasil?".

\section{Etapa 2 - Busca na literatura}

A busca na literatura foi realizada através de descritores exatos do Medical Subjects Headings (MeSH), no inglês, sendo utilizados "Quality of Life", "Job Satisfaction", "Faculty" e "Brazil" e similarmente, no português, os Descritores exatos em Ciências de Saúde (DeCS): "qualidade de vida", "Docentes", "Universidades", e o sinônimo "satisfação no trabalho". A busca dos estudos deram-se através das combinações entre os descritores utilizando os operadores booleanos AND e OR.

As bases de dados utilizadas foram as de maior significância para a temática, sendo: Literatura Latino-Americana e do Caribe em Ciências da Saúde (Lilacs), Eletronic Library Online (SciELO), Directory of Open Access Journals (DOAJ), PubMed e Academic One File.

A busca nas bases SciElo e DOAJ se deu pelos termos: "qualidade de vida AND docentes" e "satisfação no trabalho AND docentes"; na Lilacs e Academic One File "qualidade de vida AND docentes AND universidades" e "satisfação no trabalho AND docentes AND universidades"; na PubMed "quality of life AND faculty AND Brazil" e "job satisfaction AND Faculty AND Brazil".

Foram incluídos artigos, com texto completo disponível em meio online, nos idiomas português, inglês e espanhol, publicados entre janeirode 2008 a janeiro de 2018. Foram excluídos os estudos publicados fora do período estipulado e os escritos em outras línguas que não inglês, português e espanhol, assim como os estudos que não responderam à questão norteadora.

Foi realizada leitura criteriosa do título, resumo e palavras-chave dos artigos encontrados utilizando os critérios de inclusão e exclusão para préseleção dos estudos. Os trabalhos que preencheram os critérios foram lidos na íntegra, e destes, os que respondiam à questão norteadora compuseram a amostra final deste estudo. 


\section{Etapa 3 - Avaliação dos dados}

Para esta etapa, utilizou- se um instrumento de coleta de dados formulado pelos autores, contendo as seguintes variáveis: base de dados, autores, título, periódico, ano de publicação, tipo de estudo, tipo de instituição de ensino no qual o estudo foi realizado, objetivos e principais resultados.

\section{Etapa 4 - Análise dos dados}

Esta etapa resultou nas seguintes categorizações: Caracterização da amostra; Avaliação dos artigos; qualidade de vida- Fatores determinantes; Idade, tempo de serviço e relações familiares e sociais; Aspectos do sono e descanso; Diferencas entre gêneros; Diferenças entre titulações e vínculos de trabalho; Fatores de satisfação no trabalho; Fatores de insatisfação no trabalho e instituicoes privadas comparadas com as públicas.

\section{Etapa 5 - Apresentação dos resultados}

O resultado desta etapa foi a elaboração deste artigo, que apresenta, de forma clara e concreta, a revisão integrativa, colocando todas as etapas elaboradas, resultados e conclusões.

\section{RESULTADOS}

\subsection{Caracterização da amostra}

A busca nas bases de dados pesquisadas resultou em 591 artigos. Após aplicação dos filtros nas bases de dados, critérios de inclusão e exclusão, leitura dos títulos, resumos, palavras-chaves, selecionaram-se 42 artigos que foram lidos na íntegra, sendo excluídos 28 artigos (oito repetidos e 20 que não abordavam a temática deste estudo), resultando em uma amostra final de 14 artigos.

Ao realizar as buscas nas bases de dados com os descritores e os conectores booleanos, obtiveram-se 591 artigos, sendo: LILACS (10 artigos), PubMed (26 artigos), SciELO (41 artigos), DOAJ (133 artigos), Academic One File (381 artigos). As bases de dados DOAJ e One File apresentaram maior número de artigos correspondentes ao interesse deste estudo. As 
Satisfação no trabalho e qualidade de vida e de professores universitários brasileiros:

revisão integrativa

bases de dados DOAJ e SciELO obtiveram os artigos repetidos em 100\% da amostra. A PubMed não resultou trabalho na amostra final, esse fato se deu no momento da inclusão do termo "Brazil" na busca, o que limitou a busca a estudos brasileiros. A Figura 2 ilustra o fluxograma de seleção dos artigos desta revisão integrativa.

Figura 2 - Fluxograma da etapa da seleção dos artigos que compõem a amostra

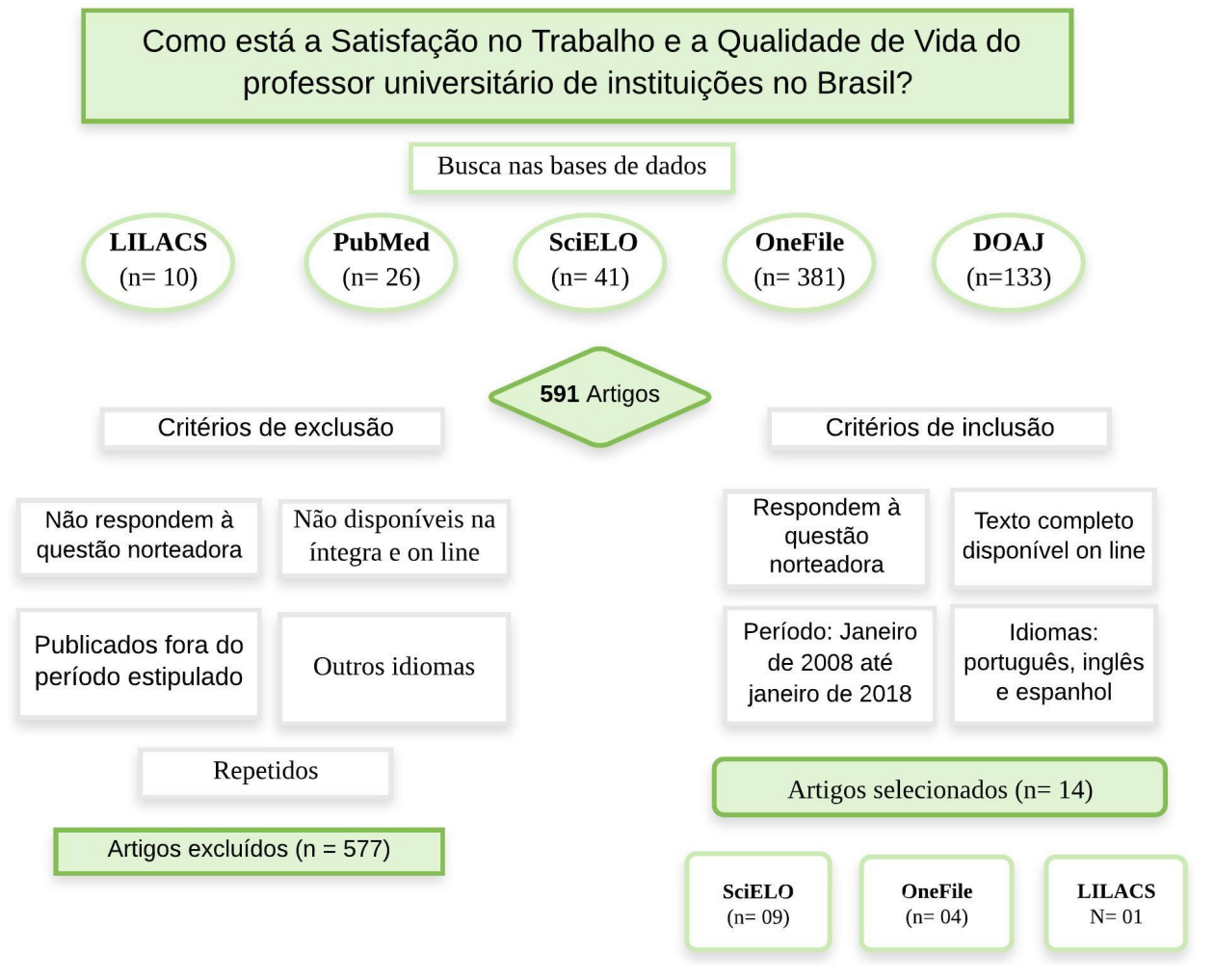

Fonte: elaborada pelos autores (2018).

Dos 14 artigos da amostra, 57\% ( $n=8)$ dos artigos abordaram o tema qualidade de vida entre os docentes, $28 \%(n=4)$ abordaram a satisfação no trabalho, e 15\% ( $n=2)$ abordaram a Organização do trabalho docente e o bem-estar subjetivo dos docentes, temas que contribuem para a temática de interesse. 
Dos oito estudos que abordaram qualidade de vida, 60\% ( $n=5)$ utilizaram o instrumento proposto pela Organização Mundial da Saúde (OMS) para avaliação da qualidade de vida, denominado World Health of Quality of Life- Bref (Whoqol- bref), que avalia os seguintes domínios: físico (dor e desconforto, energia e fadiga, sono e repouso, atividades da vida cotidiana, dependência de medicação ou tratamento e capacidade para o trabalho); psicológico (sentimentos positivos e negativos, memória, autoestima em geral e espiritualidade); relações sociais (relações pessoais, suporte e apoio); meio ambiente (ambiente em geral, segurança, transporte, recursos financeiros, condições físicas do ambiente).

Mais de 70\% (10 artigos) estudaram docentes de instituições públicas (estaduais, federais e comunitárias), e aproximadamente 20\% (3 artigos) compararam instituições privadas com públicas. Quanto à área de atuação docente, os estudados foram em sua maioria da área da saúde (45\%; $\mathrm{n}=6$ ), seguido de artigos que estudaram docentes de diversas áreas (35\%; $\mathrm{n}=5$ ), e um artigo para cada área: administração, contabilidade, humanas e engenharia.

\subsection{Avaliação dos artigos}

Os 14 artigos que compuseram esta revisão integrativa foram avaliados segundo as variáveis: base de dados; autor, título; periódico e ano; tipo de estudo e instituição de ensino; objetivos e principais resultados. Essa análise está descrita na Figura 3. 


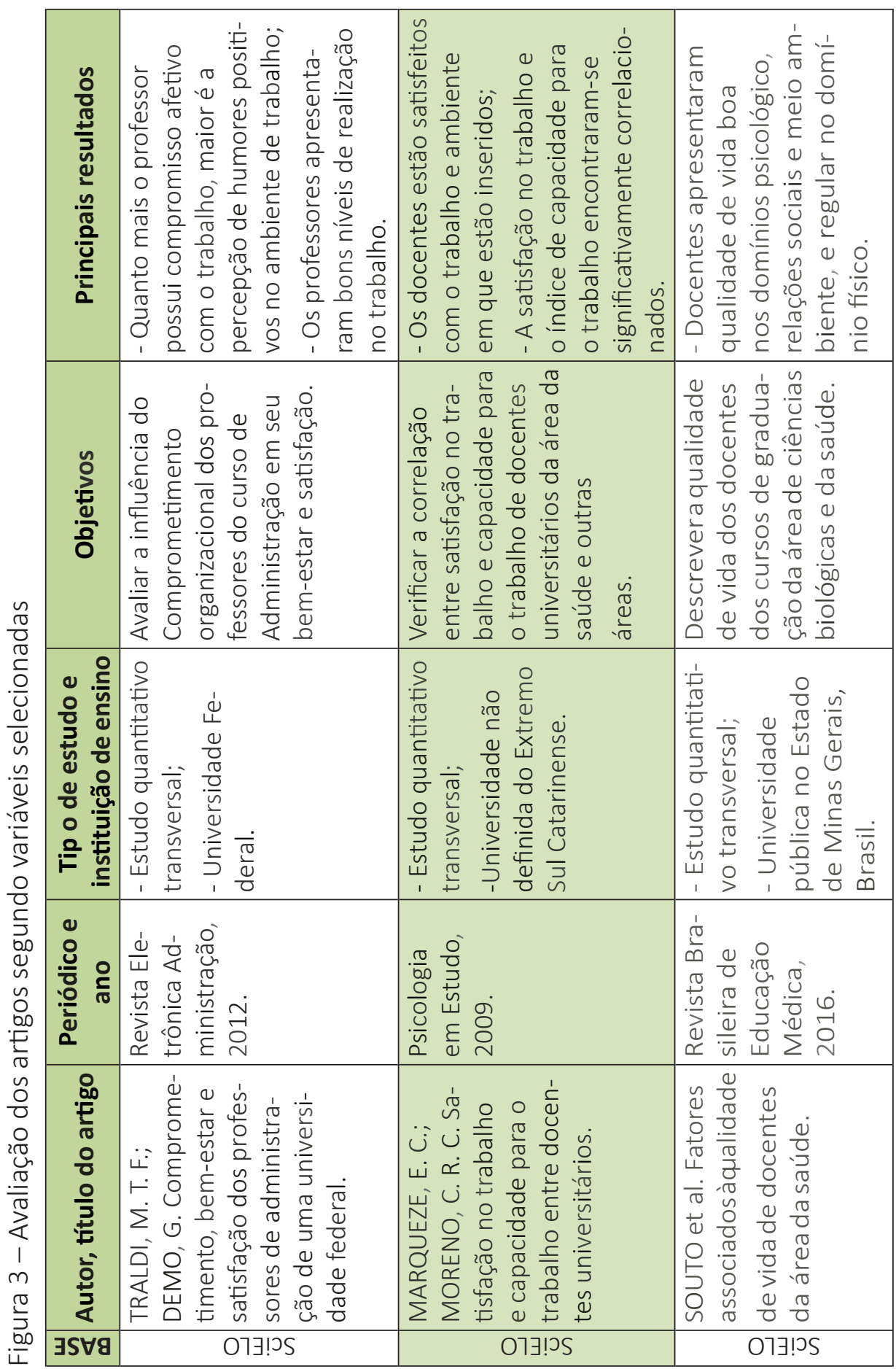




\begin{tabular}{|c|c|c|c|}
\hline 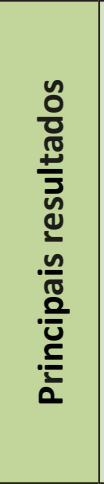 & 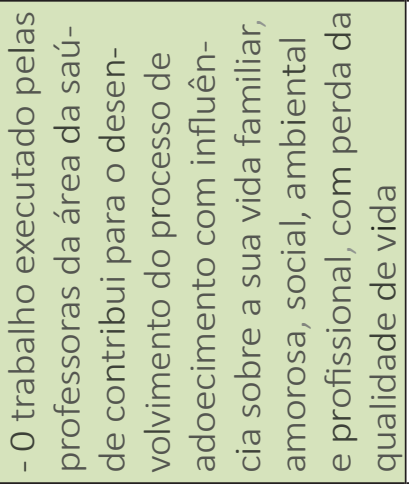 & 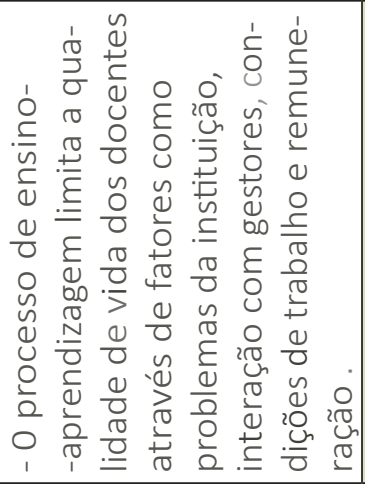 & 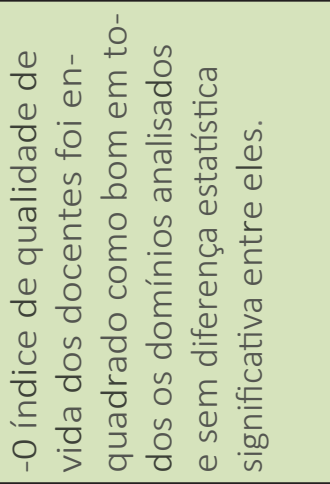 \\
\hline 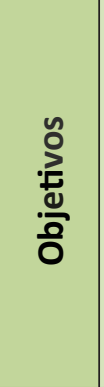 & 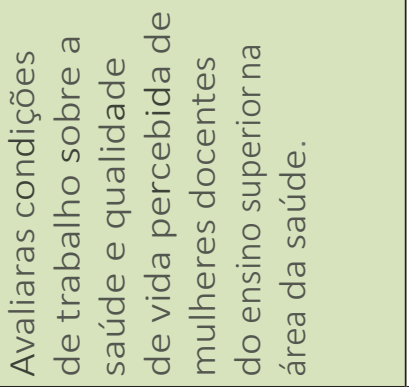 & 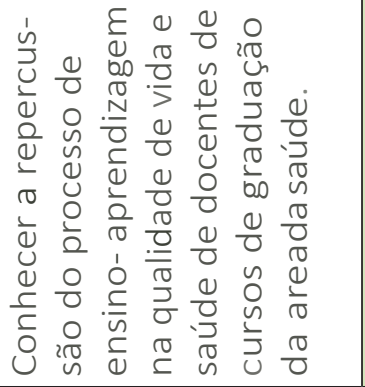 & 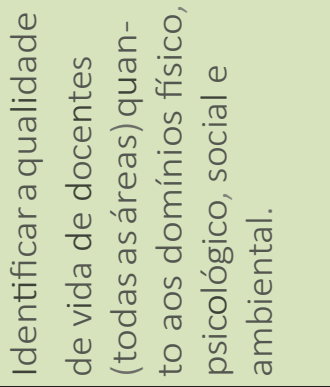 \\
\hline 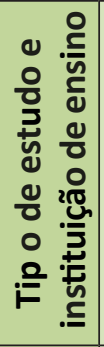 & 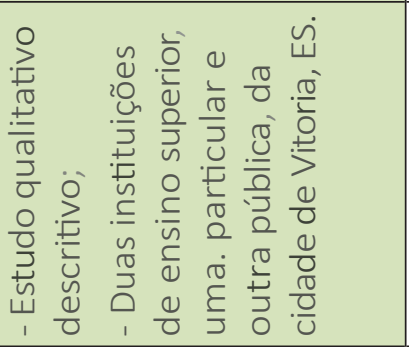 & 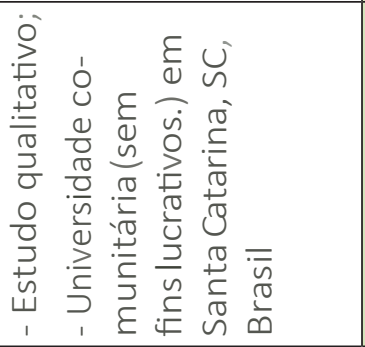 & 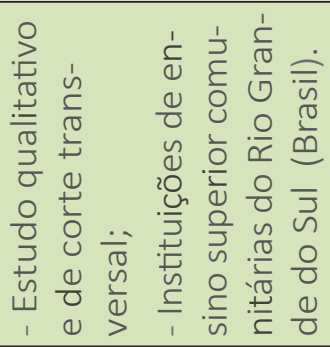 \\
\hline 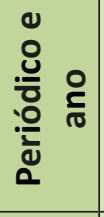 & 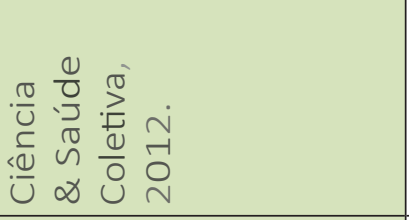 & 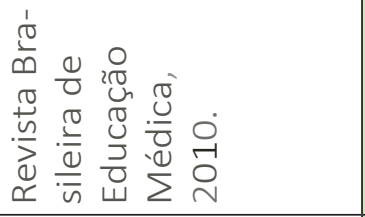 & 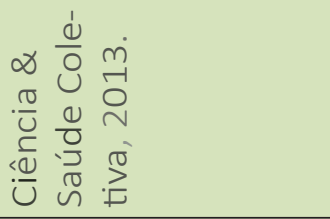 \\
\hline 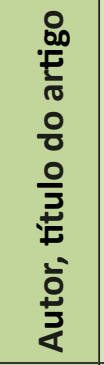 & 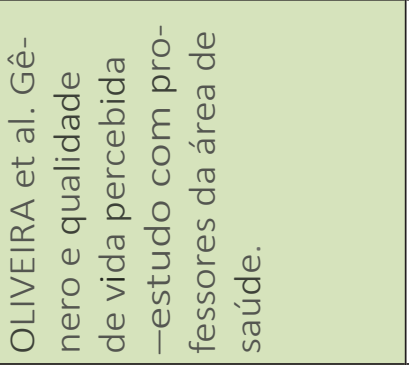 & 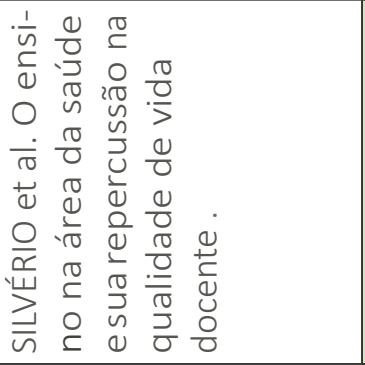 & 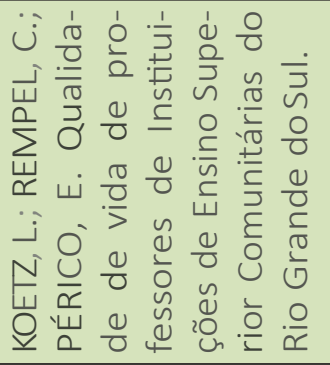 \\
\hline$\exists S \forall g$ & O7ق!כS & OTJ!JS & O7J!כS \\
\hline
\end{tabular}




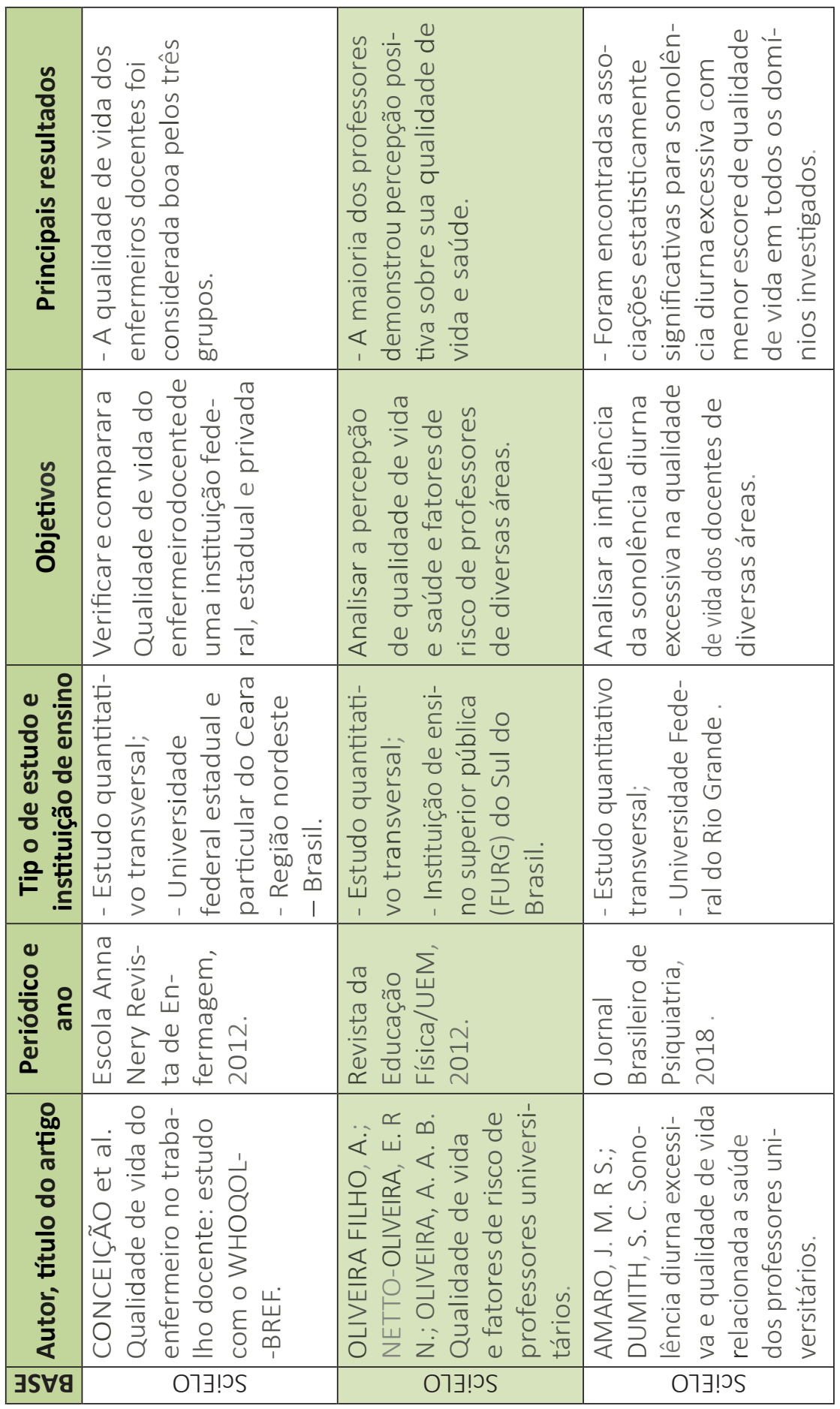




\begin{tabular}{|c|c|c|c|}
\hline 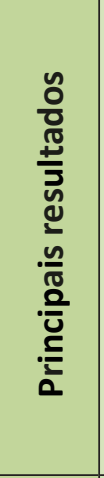 & 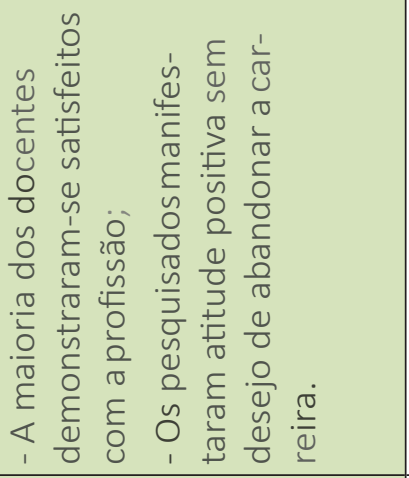 & 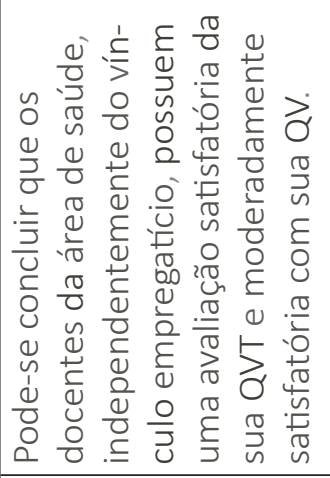 &  \\
\hline 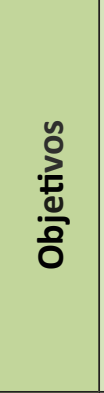 & 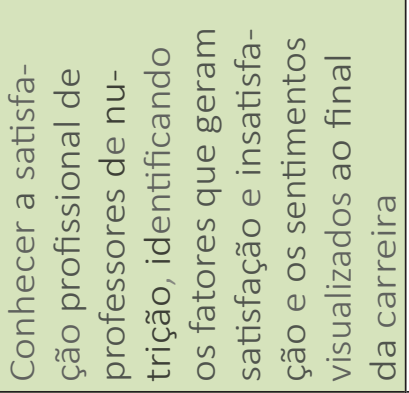 & 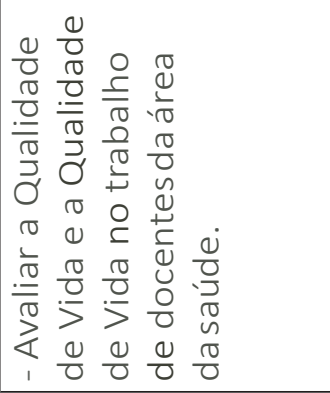 & 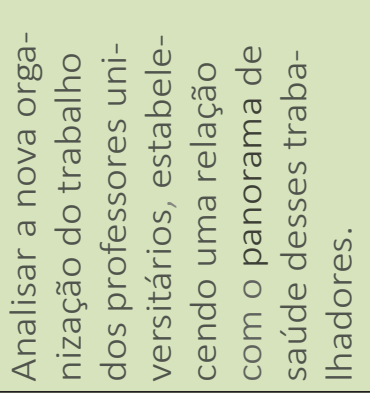 \\
\hline 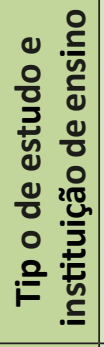 & 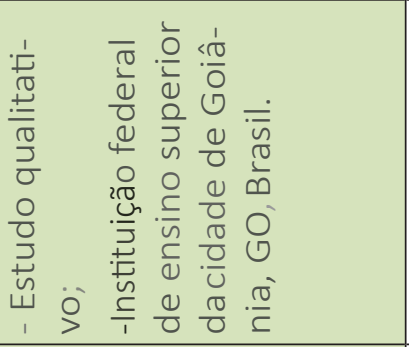 & 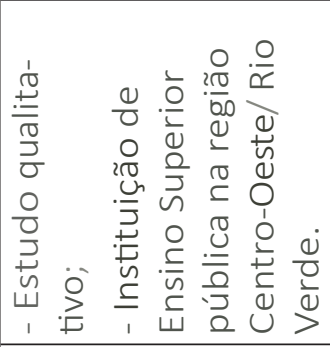 & 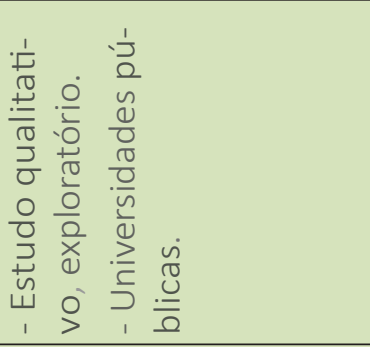 \\
\hline 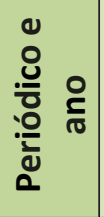 & 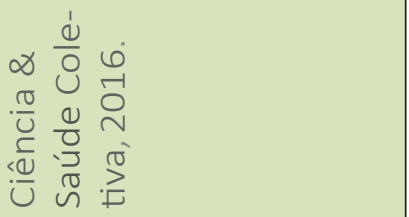 & 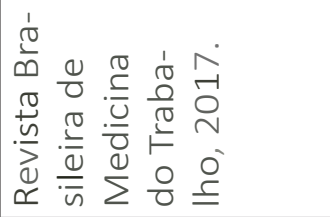 & 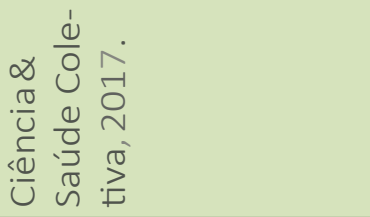 \\
\hline 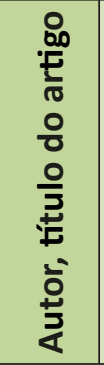 & 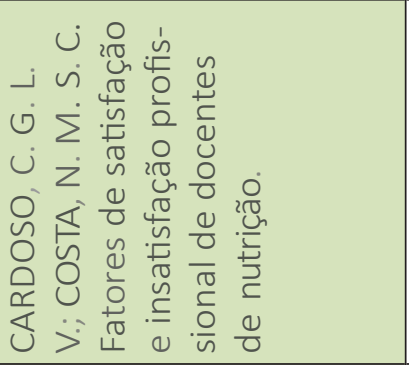 & 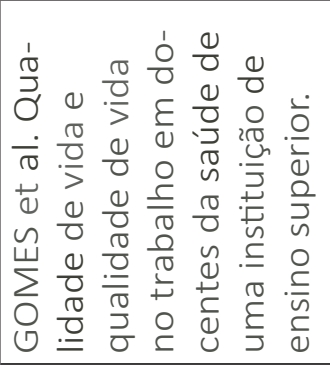 & 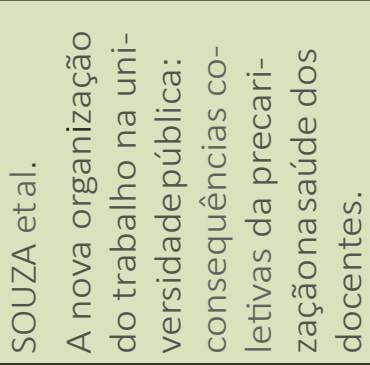 \\
\hline$\exists S \forall g$ & Sכ $\forall า 7$ & Әા!」əu૦ & ગ|!ઇચ૦૦ \\
\hline
\end{tabular}




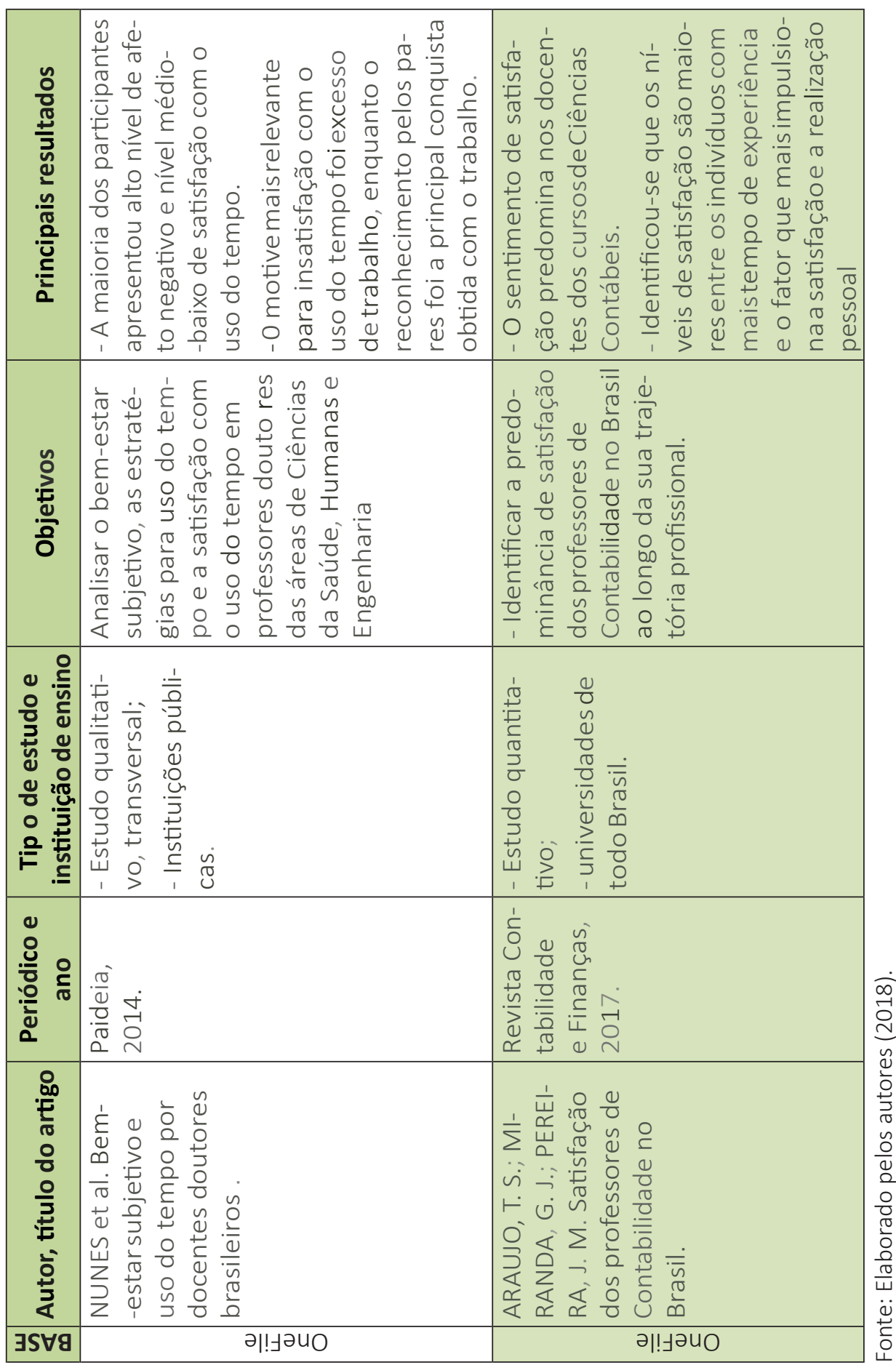




\section{DISCUSSÃO}

\subsection{Qualidade de vida - fatores determinantes}

De forma geral, os docentes universitários de instituições públicas, comunitárias e particulares apresentaram boa qualidade de vida. Alguns fatores receberam destaque por serem determinantes na qualidade de vida dos docentes.

\subsubsection{Idade, tempo de serviço e relações familiares e sociais}

Docentes mais velhos, com maior tempo de serviço, sem convívio social e familiar apresentaram menor qualidade de vida.

Souto et al. (2016) citaram relação familiar como fator determinante na qualidade de vida. Docentes casados e os que moravam com a família, mantendo atividades sociais, e com menor tempo de docência, indicaram melhor qualidadede vida comparados aos demais.

Macedo (2012) fortalece a ideia de que o apoio social é fator facilitador no enfrentamento às crises e mudanças existentes na vida, podendo aqui ser inserida a família.

Docentes mais velhos e com maior tempo de trabalho apresentaram escores inferiores de qualidade de vida no domínio físico. Esse domínio inclui aspectos como dor e desconforto, sono e repouso, atividades da vida cotidiana e capacidade de trabalho, os quais tendem a ser comprometidos pelo avançar da idade (SOUTO et al., 2016).

\subsubsection{Aspectos do sono e descanso}

Amaro e Dumith (2018) associaram a sonolência diurna excessiva com menor escore de qualidade de vida. Além disso, encontraram que um entre três professores apresentava sonolência diurna excessiva, sendo esse fato relacionado ao ritmo de vida acelerado a que esses profissionais são submetidos, no qual devem preparar e ministrar aulas, dar atenção extra a seus alunos, preparar, aplicar e corrigir provas e produzir artigos científicos.

O sono exerce papel importante na homeostasia, cujo desequilíbrio favorece o surgimento de diminuição da competência imunológica, trans- 
Satisfação no trabalho e qualidade de vida e de professores universitários brasileiros:

revisão integrativa

tornos mentais, prejuízo no desempenho físico e dificuldades adaptativas, o que pode causar aumento da vulnerabilidade do organismo e colocar a vida em risco (AMARO; DUMITH, 2018).

\subsubsection{Diferencas entre sexos}

Docentes mulheres, em geral, apresentam menor qualidade de vida em relação aos do sexo masculino.

O estudo de Oliveira et al. (2012), com docentes da área da saúde, confirmou tal situação através do relato destas sobre o excesso de trabalho extra classe, entre os quais, planejamento de aulas e atualizações pela necessidade de titulação, tudo isso associado às tarefas domésticas e dedicação à família.

Gomes et al. (2017), em seu estudo sobre qualidade de vida com 114 professores universitários da área da saúde de uma instituição pública, relataram diferenças significativas entre os sexos, nos domínios físico (dor e cansaço) e psicológico (sentimentos negativos, auto estima). Homens apresentaram maior índice de qualidade de vida em relação às mulheres, o que foi justificado pela dupla jornada de trabalho enfrentada pelas muIheres, ou seja, o trabalho formal associado às obrigações domésticas e maternas.

\subsubsection{Diferenças entre titulações e vínculos de trabalho}

Koetz, Rempel e Périco (2013) apontam que professores de instituições comunitárias, doutores em relação a especialistas, apresentaram melhores escores de qualidade de vida docente, justificado pelo fato de que os especialistas nem sempre possuem vínculos de trabalho estáveis. Já Gomes et al. (2017), em seu estudo com 114 professores universitários da área da saúde de uma instituição de ensino superior pública, relataram satisfação entre os docentes, com suas condições de trabalho, independente do vínculo empregatício.

Tal fato demonstra a necessidade de aprofundar os estudos referentes aos vínculos de trabalho. 


\subsection{Fatores de satisfação no trabalho}

Em geral, os professores apresentaram bons níveis de satisfação no trabalho. O fator de satisfação mais citado, em $60 \%$ dos artigos, foi a realização do trabalho docente.

Nunes et al. (2014) citaram que os docentes gostam do trabalho que executam, como por exemplo a produção acadêmica, a formação profissional de alunos, as contribuições para o avanço científico, e também o ganho financeiro e o reconhecimento por pares, estudantes e comunidade em geral.

Afetos positivos foram prevalentes em relação aos negativos, e a satisfação dos docentes esteve relacionada ao trabalho como fator de contribuição para conquista de objetivos pessoais (TRALDI; DEMO, 2012), assim como a realização de uma vocação, citado por Cardoso e Costa (2016) em estudo com docentes de um curso de nutrição, onde foi encontrada uma taxa superior a 70\% de satisfação no trabalho.

\subsection{Fatores de insatisfação no trabalho}

O fator de insatisfação mais citado, e que leva à precarização no trabalho (SOUZA et al., 2017 ), foi a sobrecarga de trabalho, citado em mais de $70 \%$ dos artigos da amostra.

Nunes et al. (2014) relataram que docentes se sentem insatisfeitos com o excesso de trabalho, sendo que, entre os fatores de insatisfação, destacaram-se: o tempo dedicado ao trabalho ter invadido a vida pessoal; escassez de apoio governamental para o trabalho; falta de dinheiro para o lazer devido a baixos salários e, por fim, o excesso de demandas de produção.

Outros fatores de insatisfação incluíram a estrutura física precária da universidade, sentimento de desvalorização, má relação com colegas e gestores e também com os alunos, além do desinteresse nos estudos e falta de respeito por parte desses (CARDOSO; COSTA, 2016).

O salário, de forma geral, não foi considerado fator de insatisfação. Porém, Gomes et al. (2017), em estudo com professores da área da saúde de uma instituição pública, encontraram satisfação intermediária no trabaIho e justificaram tal aspecto por insatisfação econômica/política, o que foi correlacionado a salários baixos. 


\subsection{Instituições privadas comparadas com as públicas}

Na amostra estudada, 21\% dos estudos realizaram pesquisas com professores de instituições públicas e privadas. Araújo, Miranda e Pereira (2017) relataram que 67,3\% $(n=641)$ dos professores de contabilidade apresentaram sentimentos positivos em relação ao trabalho, porém os sentimentos positivos mais representativos (entusiasmo, satisfação e realização) foram maiores nas instituições privadas que nas públicas, e o sentimento de preocupação foi maior nas instituições públicas.

Conceição et al. (2012) compararam universidades públicas, federais e particulares, em um estudo sobre qualidade de vida global com 38 docentes enfermeiros. Somente os professores da universidade privada tiveram minoria no escore "bom", porém, no geral, os docentes demonstraram-se satisfeitos. Os maiores escores foram nos domínios relações sociais, meio ambiente e psicológico, e os menores, nos domínios físico e psicológico. Isto foi justificado pelo fato de que as professoras enfermeiras também trabalham no hospital em escala noturna, e o cansaço se relaciona a especificidade do processo de trabalho, associado às atividades de ensino, pesquisa, extensão e administração.

\section{CONSIDERAÇÕES FINAIS}

Em relação à literatura estudada, a qualidade de vida geral dos docentes de instituições de ensino superior foi caracterizada como boa e a satisfação no trabalho como satisfatória.

O trabalho docente foi considerado de grande estima, o prazer em fazer o que gosta, o reconhecimento profissional e a contribuição social na formação de novos profissionais foram citados pelos docentes como fatores de satisfação.

A sobrecarga de trabalho foi o fator mais citado como causa de insatisfação no trabalho, além de ser determinante no prejuízo da qualidade de vida docente. Por esses motivos, é importante a readequação do processo de trabalho desses profissionais.

Alguns fatores ainda precisam ser minuciosamente estudados, seja por estudos epidemiológicos ou qualitativos, para verificar a associação e a 
percepção de como salários, relações interpessoais, demanda por produção científica, que são valores subjetivos citados nos trabalhos analisados, interferem como fatores determinantes tanto na satisfação profissional quanto na qualidade de vida dos docentes.

\section{REFERÊNCIAS}

AMARO, J. M. R.; DUMITH, S. C. Sonolência diurna excessiva e qualidade de vida relacionada à saúde dos professores universitários. Jornal Brasileiro de Psiquiatria, Rio de Janeiro, v. 67, n. 2, p. 94-100, jun. 2018.

ARAÚJO, T. S.; MIRANDA, G. J.; PEREIRA, J. M. Satisfação dos professores de Contabilidade no Brasil. Revista de Contabilidade e Finanças- USP, São Paulo, v. 28, n. 74, p. 264-81, maio/ago. 2017.

BRASIL. Ministério da Educação. Censo da Educação Superior - Notas Estatísticas. Diretoria de Estatísticas Educacionais (DEED), 2017. Disponível em:http://download. inep.gov.br/educacao_superior/censo_superior/documentos/2018/censo_da_ educacao_superior_2017-notas_estatisticas2.pdf. Acesso em dez 2018.

CARDOSO, C. G. L. V.; COSTA, N. M. S. C. Fatores de satisfação e insatisfação profissional de docentes de nutrição. Ciência \& Saúde Coletiva, Rio de Janeiro, v. 21, n. 8, p. 2357-64, ago. 2016.

CONCEICAO, M. R.; COSTA, M. S.; ALMEIDA, M. I.; SOUZA, A. M. A.; CAVALCANTE, M. B. P. T.; ALVES, M. D. S. Qualidade de vida do enfermeiro no trabalho docente: estudo com o Whoqol-bref. Revista Escola Anna Nery, Rio de Janeiro, v. 16, n. 2, p. 320-5, abr./jun. 2012.

GOMES, K. K.; SANCHEZ, H. M.; SANCHEZ, E. G. M.; JÚNIOR, A. L. S.; FILHO, W. M. A.; SILVA, L. A.; BARBOSA, M. A.; PORTO, C. C. Qualidade de vida e qualidade de vida no trabalho em docentes da saúde de uma instituição de ensino superior. Revista Brasileira de Medicina do Trabalho, v. 15, n. 1, p. 18-28, 2017.

KOETZ, L.; REMPEL, C.; PERICO, E. Qualidade de vida de professores de Instituições de Ensino Superior Comunitárias do Rio Grande do Sul. Revista Ciência e Saúde Coletiva, Rio de Janeiro, v. 18, n. 4, p. 1019-28, abr. 2013.

MARQUEZE, E. C.; MORENO, C. R. C. Satisfação no trabalho e capacidade para o trabalho entre docentes universitários. Psicologia em Estudo, Maringá, PR, v. 14, n. 1, p. 75-82, jan./mar. 2009. 
Satisfação no trabalho e qualidade de vida e de professores universitários brasileiros:

revisão integrativa

MACEDO, E. Domínio relações sociais da qualidade de vida: um foco de intervenção em pessoas com doenças do humor. Revista Portuguesa de Enfermagem de Saúde Mental, Porto, Portugal, n. 7, p. 19-24, jun. 2012.

NUNES, M. F. O.; HUTZ, C. S.; PIRES, J. G.; OLIVEIRA, C. M. Subjective well-beingand time use of brazilian PhD professors. Paidéia, Ribeirão Preto, SP, v. 24, n. 59, p. 379-87, set./dez. 2014.

OLIVEIRA, E. R. A.; GARCIA, A. L.; GOMES, M. J.; BITTAR, T. O.; PEREIRA, A. C. Gênero e qualidade de vida percebida: estudo com professores da área de saúde. Ciência e Saúde Coletiva, Rio de Janeiro, v. 17, n. 3, p. 741-7, mar. 2012.

OLIVEIRA FILHO, A.; NETTO-OLIVEIRA, E. R.; OLIVEIRA, A. A. B. Qualidade de vida e fatores de risco de professores universitários. Revista da Educação Física/UEM, Maringá, PR, v. 23, n. 1, p. 57-67, 2012.

SILVÉRIO, M. R.; PATRÍCIO, Z. M.; BRODBECK, I. M.; GROSSEMAN, S. O ensino na área da saúde e sua repercussão na qualidade de vida docente. Revista Brasileira de Educação Médica, Brasília, v. 34, n. 1, p. 65-73, jan./mar. 2010.

SOUZA, K. R.; MENDONÇA, A. L. O.; RODRIGUES, A. M. S.; FELIX, E. G.; TEIXEIRA, L. R.; SANTOS, M. B. M.; MOURA, M. A nova organização do trabalho na universidade pública: consequências coletivas da precarização na saúde dos docentes. Ciência \& Saúde Coletiva, Rio de Janeiro, v. 22, n. 11, p. 3667-76, 2017.

SOUTO, L. E. S.; SOUZA, S. M.; LIMA, C. A.; LACERDA, M. K. S.; VIEIRA, M. A.; COSTA, F. M.; CALDEIRA, A. P. Fatores associados à qualidade de vida de docentes da área da saúde. Revista Brasileira de Educação Médica, Brasília, v. 40, n. 3, p. 452-60, jul./set. 2016.

TRALDI, M. T. F.; DEMO, G. Comprometimento, bem-estar e satisfação dos professores de administração de uma universidade federal. Revista Eletrônica de Administração, Porto Alegre, v. 18, n. 2, p. 290-316, maio/ago. 2012.

WHITTEMORE, R.; KNAFL, K. The integrative review: updated methodology. Journal of Advanced Nursing, USA, v. 52, n. 5, p. 546-53, 2005. 
